\title{
LETRAMENTO LITERÁRIO CRÍTICO RACIAL E POLÍTICAS DE LEITURA NA EDUCAÇÃO INFANTIL EM CURITIBA
}

\author{
Paulo Vinícius Baptista da Silva (UFPR)* \\ https://orcid.org/0000-0001-9207-2439 \\ Rita de Cássia Moser Alcaraz (UFPR)** \\ https://orcid.org/0000-0002-4063-4847
}

\section{RESUMO}

Neste artigo discutimos políticas de leitura na educação infantil em Curitiba a partir da compreensão das formas como a literatura infantil opera neste complexo contexto, propondo o conceito de "literatura literária racial" como forma de interpretação dos discursos literários dirigidos à infância e distribuídos e lidos em unidades de educação infantil de Curitiba. A proposta metodológica é de interpretação crítica sobre relações raciais. A análise do conjunto de dados da pesquisa nos permite a proposta de análise a partir dos conceitos discutidos por Aparecida Ferreira (2012, 2014a) de "letramento racial" e "letramento crítico racial" e sua integração com o campo de estudos sobre os "letramentos literários". Propormos para a análise do campo da educação das relações étnico-raciais o termo "letramentos literários raciais", já que as políticas de leitura e de educação infantil, os acervos e os livros de literatura infantil ainda estão proporcionalmente estruturados por uma branquidade normativa, silenciam outras identidades que não as brancas e, muitas vezes, com formas de estereotipia e discriminação.

Palavras-chave: letramento racial; letramento literário; relações étnico-raciais; literatura infantil; educação infantil.

\section{ABSTRACT}

\section{CRITICAL RACIAL LITERARY AND READING POLICIES IN EARLY CHILDHOOD EDUCATION IN CURITIBA}

In this article we discus reading policies in early childhood education in Curitiba from the understanding of the ways in which children's literature operates in this complex context. Proposing the concept of racial literatura literacy as a way of interpreting literary discourses directed at childhood and distributed and read in early childhood education units from Curitiba. The methodological proposal

\footnotetext{
Pós-Doutorado em Análise Crítica do Discurso na Universidade Pompeu Fabra, Barcelona. Doutor em Psicologia Social pela Pontifícia Universidade Católica de São Paulo (PUC-SP). Professor na Universidade Federal do Paraná (UFPR). Curitiba, Paraná, Brasil. E-mail: pauloviniciusufpr@gmail.com

** Doutora em Educação pela Universidade Federal do Paraná (UFPR). Curitiba, Paraná, Brasil. E-mail: rita.alcaraz@gmail.com
} 
is a critical interpretation of race relations, with documentary analysis and data collection through interviews, questionnaire, observation and qualitative analysis of selected books. The analysis of the research data is based on the concepts discussed by Aparecida Ferreira (2012, 2014a) of racial literacy and critical racial literacy and their integration with the field of studies on literary literacies. We propose the analysis of the field of education of ethnic-racial relations in term of racial literary literacies, since the policies of reading and early childhood education, the collections and books of children's literature are still proportionally structured by a normative whiteness and often with forms of stereotyping and discrimination.

Keywords: racial literacy; literary literacy; ethnic racial relations; children's literature; child education.

\section{RESUMEN}

\section{LECTO-ESCRITURA CRÍTICA RACIAL Y POLÍTICAS DE LECTURA EN LA EDUCACIÓN INFANTIL EN CURITIBA}

En este artículo discutimos las políticas de lecto-escritura en la educación infantil en Curitiba a partir de la compreensión de las formas en que opera la literatura infantil en este contexto complejo. Proponemos el concepto de lecto-escrotura literária racial como una forma de interpretar los discursos literarios dirigidos a la infancia y distribuidos y leídos en la educación infantil. La propuesta metodológica es una interpretación crítica de las relaciones raciales, con análisis documental y recolección de datos por entrevistas, cuestionario, observación y análisis cualitativo de obras seleccionadas. El conjunto de datos de la investigación nos permite proponer un análisis basado en los conceptos discutidos por Aparecida Ferreira (2012, 2014a) de lecto-escritura racial y lecto-escritura racial crítica y su integración con el campo de estudios sobre lecto-esritura literárias. Proponemos para el análisis. del campo de la educación de las relaciones étnico-raciales el término lecto-escritutura literarias raciales, dado que las políticas de lectura y educación infantil, las colecciones y libros de literatura infantil todavía están estructuradas proporcionalmente por una blancura normativa, silencian otras identidades distintas a la blanca y a menudo con formas de estereotipos y discriminación.

Palavras clave: lecto-escritura racial; lecto-escritura literária; relaciones étnicas raciales; literatura infantil; educación infantil.

\section{Introdução ${ }^{1}$}

A compreensão de parte dos discursos proferidos nos documentos institucionais, os quais reconhecem a escola com condicionantes emancipatórios, é ameaçada nos limites de construções ideológicas discursivas que organizam estruturas internas sociais e são transpostas aos artefatos culturais destinados às infâncias. 0 resultado é um campo político marcado por tensões incidindo nas políticas educacionais. $^{2}$

2 A pesquisa que gerou este artigo segue as normativas de Ética da Pesquisa em Educação orientadas pelas Associação Nacional de Pós-Graduação e Pesquisa em Educação (ANPEd) e o projeto foi aprovado previamente pela equipe de autorização de pesquisa da Secretaria Municipal de Educação de Curitiba. 
A percepção de hierarquias de raça/cor no ambiente escolar influencia concepções racistas e preconceituosas, tanto implícitas quanto explícitas, por via dos discursos veiculados pelos livros e que circulam socialmente em possíveis leituras. Nesta perspectiva, a pesquisa que deu base a este artigo (ALCARAZ, 2018) analisa as políticas de leitura de livros de literatura infantil na promoção de igualdade racial.

Neste artigo buscamos analisar a política do livro infantil no município de Curitiba e possíveis interlocuções com as políticas de promoção de igualdade étnico-racial - Lei $\mathrm{n}$ 10.639/03 (BRASIL, 2003) e Lei no 11.645/08 (BRASIL, 2008), que alteraram o artigo $26 \mathrm{Ada}$ Lei de Diretrizes e Bases da Educação Nacional (LDB) - para as crianças da educação infantil (pré-escola).

As práticas de leitura e escrita são partes da cultura simbólica da comunidade desde as infâncias. Entretanto, os mecanismos de leitura no ambiente educacional passam por meio de mediações com os pares na comunidade escolar e são instituídos por programas educacionais. Eles cumprem uma função social e desajustam o leitor por meio das narrativas. A compreensão é que os contextos de letramentos no ambiente escolar utilizam, via de regra, discursos ideológicos e normativos e que sofrem influência dos discursos institucionais da política vigente.

A análise parte do conceito de letramento conforme Street $(2001,2013,2014)$, para quem a aprendizagem na esfera escolar sobre letramentos considera mais do que a apreensão fônica. 0 modelo ideológico para Street (2013) é diferente do autônomo, pois é socialmente construído e não está relacionado apenas à aquisição da escrita e da leitura de forma neutra, não obstante se ligue à cultura, às concepções de conhecimento, à identidade e às representações sociais, incorporado em diferentes contextos sociais. De todo modo, tal conceito está em um espaço constante de disputa quanto ao seu significado e também na transposição didática pelas professoras e pelos professores sobre as práticas sociais escolhidas para serem apresentadas às alunas e aos alunos na esfera escolar. Um modelo autônomo hierarquiza as relações e não se preocupa com práticas descontextualizadas da cultura local, ideológica, política e social; ele implanta uma estrutura dominante gráfica com suposições cognitivas de desenvolvimento. Para Barton (1994), os eventos de letramento podem situar a leitura e a escrita em contextos sociais. Tomando como base essa reflexão, ampliamos o conceito sobre letramentos em uma compreensão de teia dialógica e ideológica estrutural na qual as práticas discursivas se sobrepõem e (re)organizam estruturas mentais discursivas na sociedade. Isso ocorre porque muitas práticas discursivas se desenvolveram em outras esferas sociais que não a escolar (KLEIMAN, 1995; MARCUSCHI, 2001; ROJO, 2001). O letramento, para esses autores, considera as políticas e o impacto dos discursos escritos e orais. Os espaços são de uma intersecção entre as condições sociais, culturais, econômicas de uma determinada sociedade (BARTON, 1994; STREET, 2001, 2013).

Os letramentos consideram os contextos, nos quais as práticas discursivas, como a literária, podem ocupar ambientes pedagógicos e formar um ambiente relacional complexo e relevante no acesso e na formação dos indivíduos na sociedade desde as infâncias, suprimindo ou revelando a escolha à diversidade. Formulações generalistas nos documentos sobre práticas de leitura sem considerar a Educação das Relações Étnico-Raciais (ERER), por exemplo, favorecem estratégias de silenciamento, ignoram e deslegitimam a população não-branca.

0 termo "letramento literário" integra a pluralidade dos usos sociais da escrita como forma de expansão e o processo de apropriação da literatura como construção literária de sentidos (PAULINO; COSSON, 2009, p. 67). As propostas de letramentos por meio da literatura, segundo Cosson (2006), não se concentram em técnicas ou habilidades e, sim, em uma 
experiência atualizada permanentemente na formação do leitor.

Cabe refletir sobre como os discursos literários possuem a possibilidade de construir também imagens depreciativas ou afirmativas; estereotipadas ou sem estereotipias; poéticas ou não; enfim, são nas possibilidades que elas marcam os espaços simbólicos culturais das infâncias (ARAUJO, 2015). Para esta análise, mobilizamos o conceito de "letramento racial", conforme perspectiva de Ferreira (2012), forma de compreender como a raça exerce influência em experiências sociais, políticas, econômicas, educacionais. Essa autora propõe um trabalho de análise e de construção educacional de "letramento crítico racial" como forma de percepção crítica de como a raça opera para as construções de identidades sociais de raça.

Este artigo discute políticas de leitura na educação infantil em Curitiba a partir do diálogo com esses conceitos e a busca de compreensão das formas como a literatura infantil opera nesse complexo contexto, propondo o conceito de "literatura literária racial" como forma de interpretação dos discursos literários dirigidos à infância e distribuídos e lidos em unidades de educação infantil de Curitiba.

O conceito de letramento crítico racial tem impactado nas pesquisas sobre desigualdades raciais na educação, a exemplo da tese de Souza (2021, p. 325), que propõe um "letramento imagético e crítico racial" para "realmente ler e perceber os discursos presentes nas novas iconografias sobre Cultura(s) Africana(s) e Afrodescendente(s) veiculadas nos livros didáticos de História”.

A tese de Espinheira Filho (2020), que propõe o "letramento racial e literário" no livro didático de português do Ensino Médio, apresenta intertextualidade com a tese de Alcaraz (2018) e a proposta deste artigo, com mesma base nos trabalhos de Street (2013) e Ferreira (2012), propondo: a) problematizar os textos dos livros didáticos, seu contexto de produção e seus projetos de escrita literária; b) gerar mudanças nas formas de interpretação, com ressignificação de conhecimentos, construção de redes e "criar estratégias pedagógicas para apropriação discursiva antirracista" (ESPINHEIRA FILHO, 2020, p. 124).

\section{Metodologia}

Compreendemos a importância na formação identitária da afirmação linguística local dos discursos sociais, que representam a comunidade em que se vive. 0 espaço simbólico é fundante nas relações de poder e de dominação. Tal relação é afirmada nas palavras de Fanon (2008, p. 33):

Atribuímos uma importância fundamental ao fenômeno da linguagem. É por esta razão que julgamos necessário este estudo, que pode nos fornecer um dos elementos de compreensão da dimensão para-o-outro do homem de cor. Uma vez que falar é existir absolutamente para o outro. $O$ negro tem duas dimensões. Uma com seu semelhante e outra com o branco. Um negro comporta-se diferentemente com o branco e com outro negro. Não há dúvida de que esta cissiparidade é uma consequência direta da aventura colonial.

A metodologia adotada nesta pesquisa (ALCARAZ, 2018) é uma perspectiva de análise das relações raciais orientada por uma perspectiva crítica e ancorada nos estudos de pesquisadoras e pesquisadores brasileiros. A perspectiva decolonial adotada vem da adoção dos conceitos formulados por pesquisadoras mulheres negras brasileiras: Eliane Debus (2017), sobre a "literatura infantil de temática africana e afro-brasileira"; e Aparecida de Jesus Ferreira (2012, 2014a), sobre "letramento racial" e "letramento racial crítico". A proposta metodológica denominada de "interpretação crítica sobre relações raciais: uma análise, eminentemente de base discursiva, com o objetivo de explorar nuances e possibilidades de mobilização de um conceito para a interpretação das desigualdades de natureza racial", formulada por Araújo e Silva (2020, p. 318), é atualizada e discutida. A proposta é de uma análise que interpela as hierarquias estabe- 
lecidas por normatizações e busca se afirmar decolonial pela construção da área de estudos críticos sobre relações raciais e educação das relações étnico-raciais no Brasil, campo de estudo que vem produzindo interpretações e conceitos próprios e um trabalho contínuo de incorporação no pensamento social brasileiro do ponto de vista de análise de pesquisadoras e pesquisadores negras e negros.

A metodologia incorpora diferentes procedimentos e instrumentos de pesquisa de forma a analisar as formas de estabelecimento de relações sociais de desigualdade, a afirmação de discursos de sujeitos "periféricos" e a compreensão das desigualdades sociais como eminentemente interseccionais. No caso deste artigo, a articulação da análise se dá entre o eixo de raça e o eixo de idade, ao analisar políticas de literatura que difundem discursos dirigidos à infância.

A pesquisa da qual deriva este artigo (ALCARAZ, 2018) utilizou-se de uma série de procedimentos de coleta de dados: 1) Análise documental, que coletou normativas e documentos: a) histórico, funcionamento, acervo, distribuição, legislação, editais e resoluções de programas de distribuição de livros pelo Governo Federal; b) da Secretaria Municipal de Educação de Curitiba: histórico da Educação Infantil, acervo, Plano Municipal de Educação e documentos relativos às políticas de leitura, literatura e bibliotecas de Curitiba, Cadernos Pedagógicos, Parâmetros e indicadores de Qualidade para os Centros Municipais de Educação Infantil, Cadernos SEP e legislação; 2) Revisão de literatura sobre relações raciais na literatura infantil, com busca e análise de artigos, teses, dissertações, livros e capítulos de livros; 3) Entrevistas com gestoras da Comissão de análise e escolha dos livros em Curitiba para a Educação Infantil da Rede Municipal de Curitiba, com o intuito de conhecer o funcionamento dos Programas literários que incidem na aquisição de livros nos Centros Municipais de Educação Infantil: objetivos dos programas, critérios de avaliação, definição de listagens de livros, in- dicação de compras; 4) Coleta de documentos com a bibliotecária responsável pelos livros da Secretaria Municipal de Educação de Curitiba; 5) Aplicação de questionário semiestruturado para as pedagogas e professoras responsáveis nos Centros Municipais de Educação Infantil (CMEIs), Centros de Educação Infantil (CEIs) e Escolas Municipais em que existia a oferta da educação infantil; 6) Acesso a duas unidades de Centro Municipal de Educação Infantil, uma unidade conveniada e uma escola municipal em Curitiba, para observação das políticas de leitura em desenvolvimento nas instituições, consulta, análise dos livros dispostos no acervo conforme a escolha dos alunos. As escolhas das unidades de educação infantil se deram por meio da disponibilidade delas. Os aceites foram de dois locais mais centrais e outros dois periféricos. Neles comparamos os livros que chegaram por intermédio do programa do livro do governo federal e compras por programa próprio da Secretaria Municipal de Educação. Solicitamos que as crianças escolhessem, em meio ao acervo disposto nas unidades com diferentes estratégias o que elas desejavam ler. A amostra, resultado da coleta nas unidades escolares, foi de 92 livros infantis selecionados pelos alunos com os seus professores, dentre os utilizados nas unidades.

\section{Sintese de resultados}

Apresentaremos alguns pontos bastante sintetizados do conjunto de resultados que coletamos, selecionados pela sua relevância para o foco deste artigo, a discussão sobre o letramento literário e o letramento racial e a relação entre a política de literatura infantil e a educação das relações étnico-raciais.

Desde a formação de professores pela Secretaria Municipal de Educação de Curitiba (SME), as práticas de mediação de leitura seguem as diretrizes e são planejadas, como a contação da história, seguindo a importância dos gêneros textuais, além de nas orientações também enfatizarem diferenças para o jogo 
literário. Há cuidado quanto aos critérios e à evidência deles para a formação de professores da rede.

Nos textos orientadores também são incentivadas as rodas de conversa, a leitura dos livros para os alunos e formas de mediação de leitura com planejamentos específicos compartilhados para incentivar outras ações. São indicadas experiências compartilhadas para as séries e nos espaços de bibliotecas (denominadas "farol do saber" em Curitiba, em razão de sua arquitetura) com o objetivo de promover o espaço cultural e de leitura.

Há um cuidado na SME quanto aos critérios e à evidência deles para a formação de professores da rede. Desde a formação de professores pela SME, as práticas de mediação de leitura seguem as diretrizes nacionais para a infância e estão em um manual de parametrização de qualidade. São planejadas com critérios como a contação de histórias, seguindo a importância dos gêneros textuais, com ênfase nas diferenças para o jogo literário. No entanto as centenárias tradições africana e africana da diáspora de contação de histórias, por exemplo, não são consideradas no documento, há um silenciamento. No texto existe a descrição de ações: as rodas de conversa, a leitura dos livros para as crianças e formas de mediação de leitura com planejamentos específicos compartilhados para incentivar outras ações.

Cotejamos o discurso das gestoras do programa de leitura da SME com documentos da própria Secretaria e no Quadro 1 sistematizamos os fragmentos selecionados da entrevista para compararmos com os documentos.

Quadro 1 - Comparação entre os dados documentais e entrevistas de gestoras

\begin{tabular}{|c|c|}
\hline $\begin{array}{l}\text { CADERNO PEDAGÓGICO } \\
\text { ORALIDADE }\end{array}$ & $\begin{array}{c}\text { REDE MUNICIPAL BIBLIOTECA CURITIBA - } \\
\text { CADERNO PEDAGÓGICO }\end{array}$ \\
\hline $\begin{array}{l}\text { Na formação de leitores, "é impres- } \\
\text { cindível que, desde os primeiros } \\
\text { anos de vida, as crianças tenham } \\
\text { oportunidade de acesso a bons } \\
\text { textos, dos clássicos aos modernos, } \\
\text { considerando os diversos tipos e } \\
\text { gêneros" (CURITIBA, 2009, p. 63). }\end{array}$ & $\begin{array}{l}\text { "Dessa forma, entende-se que deve ser oportunizado o contato } \\
\text { da criança com o livro de forma mediada, procurando despertar } \\
\text { o gosto pela leitura e proporcionar a ela momentos de vivência } \\
\text { no espaço da biblioteca." (CURITIBA, 2014, p. 65). }\end{array}$ \\
\hline \multicolumn{2}{|r|}{ ENTREVISTA } \\
\hline \multicolumn{2}{|c|}{$\begin{array}{l}\text { “Que tenham uma boa qualidade de texto, que não aquele texto empobrecido, desconexo, que tenha } \\
\text { um começo, meio e fim, não infantilizado, na questão. Não é por que tenha que ser para criança é } \\
\text { que o livro tenha que ser bobo, muito pelo contrário, um texto que acrescente, e que tenha autores } \\
\text { conhecidos, que tenham esse repertório, sabemos que ele são grandes referências, mas não são as } \\
\text { únicas, a gente busca isso, que trabalhe com a qualidade de ilustração e projeto gráfico que a gente sabe } \\
\text { que a leitura da imagem, ela tem que dialogar com o texto, ampliar a imaginação imagem que entenda } \\
\text { como arte, que não traga estereótipo, a gente tem esse cuidado, que tragam as boas adaptações de } \\
\text { clássico, não aquele clássico para se vender, onde, nem sei se pode falar isso aqui, mas aqueles contos } \\
\text { de } 1,99 . \text {." (Entrevista realizada com a Comissão de livros). }\end{array}$} \\
\hline
\end{tabular}

Fonte: Alcaraz (2018, p. 122). 
Os discursos referenciados nos documentos e na entrevista são de anos distintos, os grupos internalizaram essas representações, seguindo os critérios institucionais. Comparativamente, a consolidação da SME para as políticas de leitura literárias segue os indicados também pelo Programa Nacional Biblioteca na Escola (PNBE) em diferentes momentos.

A análise dos documentos e das entrevistas revela que a linha de argumentação desenvolvida ao longo dos anos pelo PNBE consolida a teoria literária para as infâncias e reflete na política do município de Curitiba por meio das políticas e dos critérios elencados na seleção dos livros. Uma estrutura de seleção de livros adquiridos com personagens brancas ganha ao longo do tempo dimensões maiores. Naturalizam-se as opiniões sociais acerca da branquitude como norma nas imagens e nos discursos, compartilhados por modelos mentais pessoais (VAN DIJK, 2015). Como consequência, a branquitude gradativamente se insere em tantos espaços discursivos, inclusive na literatura para as crianças, reafirmando o branco como modelo de humanidade.

Os dados da análise de personagens nas ilustrações de amostra de livros em nosso trabalho de campo sustentam a afirmação de uma maioria de personagens brancos. Vivemos uma suposição de infâncias e destinamos às crianças aquilo que os adultos escolhem como seguro, provável e bom. Influenciamos diretamente as culturas simbólicas das infâncias, enquanto elas significam as histórias, descontroem, reinventam em esforços e complexidades que nenhum método estatístico pode fracionar. "Os gramáticos da narrativa que se cuidem. As orações terminam com pontos finais. As histórias não." (HUNT, 2010, p. 149). Por isso é fundamental garantir uma pluralidade nas representações mais ampla como referências. Não precisamos controlar a literatura, mas sugerir outros diálogos com as estruturas que a determinam.

O questionário que foi enviado para 199 unidades de educação infantil (3 a 5 anos) ge- rou 28 respostas de representantes de equipes pedagógicas, das quais 89\% afirmaram que desenvolviam projetos específicos de leitura e 91\%, que possuíam orientações sobre Educação das Relações Étnico-Raciais. Uma primeira consideração é que a maioria das respondentes apresentam informações positivas em relação ao questionário enviado, mas o total de resposta foi somente $14 \%$ do total. Podemos levantar a hipótese de que as respostas foram dadas por equipes pedagógicas que tinham mais o que responder ao questionário.

Entre as políticas, os programas e os projetos de leitura da SME, na área de literatura na Educação Infantil é ofertado um curso específico de leitura literária. Paralelamente ao curso mantém-se um projeto denominado "Crianças de Curitiba". Segundo as gestoras da Secretaria Municipal de Educação, neste projeto as professoras trabalham diversos aspectos relativos à importância da leitura, à leitura diuturna, à importância da fruição, à ampliação do repertório. Neste projeto são confeccionados livros pelas crianças e alguns são escolhidos e impressos posteriormente para o projeto, e as crianças leem as histórias umas para as outras.

A leitura é compreendida no município, segundo a pesquisa, como uma atividade permanente na rede. Ela está inserida em documentos, como os parâmetros e indicadores de qualidade. A sugestão às professoras e aos professores é que a criança seja convidada a ler, a experienciar o livro. Por isso, os critérios na escolha dos livros a serem adquiridos pela unidade são realizados conforme a indicação da SME, com a participação das professoras e das pedagogas, de representantes institucionais.

À pergunta sobre os livros utilizados no trabalho com a diversidade, o livro A Menina Bonita do Laço de Fita (MACHADO, 2011) apareceu 18 vezes, e os demais livros mais citados foram O Cabelo de Lelê (BELÉM, 2012), Bruna e a Galinha d'Angola (ALMEIDA, 2004), As Tranças de Bintou (DIOUF, 2004), Ana e Ana (GODOY, 2004). 0 conjunto de 46 obras citadas pelas representantes de equipes pedagógicas 
de instituições de educação infantil de Curitiba possibilita a identificação de quatro grupos (que não esgotam as 46 obras, visto que não foram analisadas uma a uma): a) livros que tratam da diversidade étnico-racial e que representaram avanços quando de sua publicação, mas apresentam limites e são bastante datados, entre os quais o mais citado, A Menina Bonita do Laço de Fita (MACHADO, 2011), e $O$ Menino Marrom (ZIRALDO, 1986); b) obras da literatura infantil de temática africana e afro-brasileira que têm em seus temas tramas, narrativas, personagens principais, uso de vocabulário, narradores, contexto de desenvolvimento, características conjugadas ou não, que configuram uma produção voltada para a valorização destes aspectos de africanidades. As obras citadas mais frequentemente, como Obax (NEVES, 2010), Tanto, tanto! (COOKE, 1997), Karingana wa Karingana: Histórias que me Contaram em Moçambique (BARBOSA, 2012), Cadê? (LIMA, G., 2009), Chuva de Manga (RUMFORD, 2005), Gosto de África, Histórias de lá e daqui (SANTOS, 2000), Histórias da Preta (LIMA, H., 1998), podem ser classificadas neste grupo, que constituiu a maioria das obras listadas; c) alguns livros que tratam da diversidade racial ou da diversidade de forma prescritiva e relacionada com uma perspectiva simplista e/ou ingênua, como, por exemplo Diversidade (CIRANDA CULTURAL, 2010), Ninguém é igual a ninguém (OTERO, 2008), Direitos e Deveres das Crianças (SAGEZZA, 2008); d) livros que não têm nenhuma relação com educação das relações étnico-raciais, como, por exemplo Diário de um Banana (KINNEY, 2008). Não é intuito nem há espaço para fazer uma análise pormenorizada de cada uma das 46 obras, algumas inclusive às quais não temos acesso, por isto trazemos somente alguns exemplos e nos atemos à análise de aspectos específicos e de algumas características relevantes para a discussão de letramento literário e sua interface com a educação das relações étnico-raciais.

No caso de Diário de um Banana (KINNEY, 2008) ser classificado como um livro para se trabalhar com a ERER consideramos um equívoco. As respostas sobre não possuir orientação no trabalho com ERER, 9,7\%\% do total, derivam principalmente das respostas das unidades conveniadas e podem revelar uma falha no diálogo formativo profissional entre a SME e estas instituições. Nas respostas das unidades conveniadas foram designados menos livros e com menor incidência das obras de literatura infantil de temática africana e afro-brasileira.

\subsection{A análise de livros selecionados}

Como forma de discutir as diferentes expressões discursivas expressas em duas listagens diferentes de livros, a de 46 obras indicadas por equipes pedagógicas da educação infantil como obras de referência para o trabalho com ERER na educação infantil e as 92 presentes em bibliotecas escolares e indicadas pelas crianças em quatro unidades escolares de Educação Infantil, apresentaremos uma análise qualitativa de quatro livros, como forma de subsidiar a discussão sobre as heterogeneidades dos discursos dos livros, que podem proporcionar diferentes forma de "letramento literário racial".

Segundo Eliane Debus (2016), a recepção do livro pelas crianças é importante pelas percepções sobre o imaginado em um processo comunicativo por meio dos sentidos culturais e de estruturas sociais impressas na literatura infantil. Menina bonita do laço de fita, de Ana Maria Machado (2011), foi o mais lembrado pelas educadoras no trabalho com as crianças. Foi publicado na década de 1980 e se destaca por causa da valorização de aspectos da personagem título, uma menina negra. No entanto, possui afirmações como: "Os olhos pareciam duas azeitonas pretas [...]. A pele escura e lustrosa, que nem o pelo da pantera negra quando pula na chuva." (MACHADO, 2011, p. 5). No livro, os predicativos são dados como enunciados de valorização da protagonista negra. Tal relação enunciativa entre a humanidade e a animalidade ocorre de maneira inexpressiva com as personagens brancas, sendo incomum a aproximação delas com características de 
quaisquer animais para denotar beleza. Ainda, a personagem "menina" não possui nome e a caracterização é dada pelo laço de fita e pela cor de sua pele, paralelo difícil de acontecer com personagens brancas. Construir o elogio da menina negra a partir de um animal antropomorfizado, o coelho branco, é uma situação que merece reflexão. Essas características parecem inventivas e criativas e despertam a imaginação em um jogo, no qual o coelho insistentemente tenta ficar preto. Apesar de algumas divergências entre interpretações da obra, quando nela é enunciada a cor preta em vez de negra como adjetivo para a menina, compreendemos como contraste semântico com a cor branca do coelho. Nas respostas dela ao coelho sobre como ele poderia ficar preto, também observamos uma identidade em construção da menina, pois a única a responder tomando a família como referência para a cor de pele é a mãe dela. A mãe é denominada de "mulata", ${ }^{3}$ termo comum no discurso brasileiro que, via de regra, camufla a negritude e a carrega de estereotipias. No decorrer da narrativa, o coelho se apaixona por uma coelha "escura como a noite" e "ela o acha uma graça" (MACHADO, 2011, p. 10); eles se casam e acabam tendo vários filhos e filhas. A mensagem sobre a mestiçagem no Brasil fica implícita, pois do casamento entre os coelhos, apenas uma filha nasce preta. Lembramos que esse processo de mestiçagem não foi harmonioso e fez parte de um processo histórico de colonização na exploração de não-brancos. Em nossa análise, portanto, a referida obra deve ser lida como uma obra datada, que teve um papel relevante no ano de sua publicação por trazer uma personagem negra como principal e tentou valorizar alguns de seus atributos estéticos, mas que tem muitas limitações para a ERER, mantendo formas de hierarquia racial em seu discurso.

Outra obra lembrada pelas educadoras foi o livro Cadê?, de Graça Lima (2009), tomado como exemplo de obra que faz parte do grupo

3 Indicamos o artigo Sobre a invenção da mulata, de Mariza Corrêa (1996). de literatura infantil de temática africana e afro-brasileira, neste caso pela personagem central e a narrativa

O livro de Graça Lima (2009) harmoniza a narrativa e a imagem, o menino que se esconde da mãe em espaços da casa, e apresenta uma aventura em meio a grandes animais. A ação da brincadeira nas cenas do livro instaura um jogo. Assim, a pergunta que se repete pela mãe, “Cadê?", seguida de adjetivos carinhosos, é o signo para iniciar a brincadeira, desde o título inicial na capa do livro.

Criança escondida. Já conhece todos os esconderijos da casa e retorna a eles como a um lar onde se está seguro de encontrar tudo como antes. 0 coração palpita-lhe, ela prende a respiração. Aqui ela está encerrada no mundo material. [...] A mesa de jantar, debaixo da qual ela se pôs de cócoras, a faz transformar-se em ídolos de madeiras em um templo onde as pernas talhadas são as quatro colunas. Por preço algum ela deve ser encontrada. (BENJAMIN, 1984, p. 107-108).

Com efeito remete a Benjamin (1984, p. 101): "[...] a grande lei que, acima de todas as regras e ritmos particulares, rege a totalidade do mundo dos jogos [é] a lei da repetição. Sabemos que para a criança ela é a alma do jogo; que nada a torna mais feliz do que o 'mais uma vez." Ele também sugere como o espaço no interior da casa pode ser transformado em brincadeira pela criança. A obra foi escolhida para análise, pois estamos diante de aspectos textuais com os quais acreditamos que as crianças se identifiquem no encontro com o diálogo com as imagens. Consideramos que a realização dessa interação não advém de um controle textual, mas de como as crianças acessam o texto, o que se dá de várias maneiras, e quanto mais possibilidades plurais e representativas lhes for possível conhecer, imaginar e brincar, mais representações ocuparão os espaços simbólicos em seus universos narrativos e literários. As crianças "habitam nas imagens" (BENJAMIN, 1984, p. 65).

Alguns dos livros citados no trabalho com a diversidade não aparecem na pesquisa de campo, mas são repetidos como resposta 
pelas educadoras nas sugestões sobre quais livros desejavam utilizar nas unidades. $0 \mathrm{cru}$ zamento dos dados leva a crer que para além das respostas há ainda um longo caminho de reflexão sobre a literatura e a ERER. Ele passa pela formação de professores sobre os livros disponibilizados sob o pretexto da diversidade racial, no debate sobre os privilégios da branquitude, na reflexão sobre as formas de exclusão, e fazem parte do ideário social e cultural que, por ora, organizam o que deve ser lido e impactam as culturas infantis. Tomamos como exemplo o livro Cadê? de Graça Lima (2009), encontrado no acervo do PNBE, para refletir sobre a importância da literatura para as crianças no espaço escolar.

Outra obra que faz parte do grupo que coloca narrativas centradas em africanidades é Bruna e a galinha d'Angola (ALMEIDA, 2004), que teve analisado seu uso em prática pedagógica de educação das relações étnico-raciais em uma turma de crianças de 4 anos de uma instituição em Porto Alegre, e de análise pela voz de uma criança negra, por isto transcrevemos parte da análise aqui:

O livro traz diversos aspectos de africanidades (em seu enredo, nas personagens, nas ilustrações), ao propor um 'retorno da diáspora', levando os leitores num caminho permeado por mitos africanos. Dois aspectos foram enfatizados nos resultados observados na EMEI: a relação de acolhimento e respeito entre a personagem Bruna e sua avó, foco de comentário de aluno de 4 anos sobre a obra, e os grafismos africanos, em destaque nas produções em desenhos dos alunos a partir da leitura do livro. (SILVA; SOUZA, 2013, p. 42).

$\mathrm{Na}$ análise desses autores, os livros na instituição estudada, e em outros exemplos apontados na literatura, organizam práticas pedagógicas de letramento literário racial que transcendem o objeto livro. Em especial em uma das instituições visitadas para coleta de dados, um Centro Municipal de Educação Infantil (CMEI), observamos muitas dessas práticas de mediação de leitura, a exemplo de como a contação de histórias com o uso de livros que continham personagens negras eram transformada em atividades estampadas nas salas, nos corredores, visíveis para quem chegasse até a unidade; eram muitas representações de o Cabelo de Lelê (BELÉM, 20012), de Bruna e a Galinha d'Angola (ALMEIDA, 2004), Chuva de Manga (RUMFORD, 2005), Obax (NEVES, 2010). Neste local, de maneira específica, percebemos que o planejamento das leituras com as crianças transforma o espaço escolar e pode modificar as relações. 0 exemplo de leitura literária como prática reconhecia como legítima a possibilidade de livros com personagens negras a circular por meio das eventuais atividades penduradas no ambiente do CMEI. A experiência singular da leitura apresentou uma interpretação que indicava o trabalho com a diversidade. Não participamos da organização e estratégia da mediação de leitura na unidade, entretanto, era evidente a relação do ambiente com o contexto social que informava ao leitor uma ampliação no círculo de livros conhecidos pelos alunos, professoras e pedagogas na inclusão de personagens negras.

Por outro lado, tanto os acervos, de uma forma geral, quanto as formas de mediação observadas e relatadas em outras instituições de educação infantil apresentavam outras formas de organização discursiva. Um dos exemplos, o livro $O$ rei bigodeira e sua banheira, de Audrey Wood (2010), traduzido por Gisela Maria Padovan, foi obra adotada em Curitiba e foi encontrado em nosso trabalho de campo, compondo um acervo dirigido para a educação infantil. Na obra, destaca-se a profusão de imagens por meio de ilustrações de uma corte europeia em traços que exageram o estilo rococó/Luís XV, especialmente presentes a figura de rei, rainha e um pajem (personagem criança) que enche a banheira incansavelmente a história inteira. Sobre as águas um banquete é servido pelo pajem e são vários apelos para que o rei saia da banheira. 0 discurso literário não condena o trabalho infantil, as relações e os caprichos do rei são atendidos, os personagens representados nas ilustrações, todos brancos com 
bochechas rosadas, estão em uma narrativa, deslocados no espaço-tempo, em um ambiente eurocêntrico e que naturaliza o desrespeito aos direitos da criança como consideramos hoje, dando ao discurso literário um caráter ideológico e neutro. "No matter how simplistic it may appear, no book is innocent of ideological implications." (STEPHENS; McCALLUM, 2011, p. 359). ${ }^{4}$ A literatura infantil não é isenta de intenções, ela pode ser plástica, emoldurada em diferentes cenários, e podemos ter histórias de reis e rainhas sem se perpetuar as marcas estéticas de superioridade da supremacia branca e a relação de superioridade entre adultos e crianças. 0 caráter de neutralidade literária apoiado na crença e modos de uma literária universal guarda também a influência europeia como um dos aspectos de herança da "cultura brasileira". Um dos importantes movimentos de rompimento literário em busca de uma literatura nacional, como o Modernismo, em 1922, teve suas bases nas vanguardas europeias, século XX, e nos autores nacionais, a influência dos que estudaram na Europa e disseminaram essas ideias. Afirmamos que a literatura nacional tem como base concepções colonizadas, quando sob a égide da neutralidade e da universalidade privilegiam a brancura como adjetivo. Assim, a impressão da branquitude influencia as infâncias e seus jogos e contribui para as desigualdades estruturais. A narrativa que conjuga textos e imagens da obra mantém aspectos da colonialidade e traz em seu repertório uma interculturalidade branca como marca simbólica na literatura.

Outro exemplo que apresentamos, com estrutura discursiva que também opera para reproduzir e produzir hierarquia racial, mas numa outra chave de organização discursiva, não pela normatividade branca, mas pela estereotipia da personagem negra, será objeto desta análise.

\section{O livro Quando os tam-tans fazem tum-tum,}

4 "Não importa quão simplista possa parecer, nenhum livro é inocente de implicações ideológicas." (STEPHENS; McCALLUM, 2011, p. 359, tradução nossa)." do autor Ivan Zigg (2013), foi um dos livros aprovados no edital do PNBE de 2014, na categoria 1, Educação Infantil para crianças de 0 a 3 anos. Interpretamos no discurso da obra exemplos de imagem estereotipada, com marcas racistas. 0 personagem é apresentado com traços físicos dos negros/negras desumanizados, suas trapalhadas sugerem brincadeiras que fazem o público rir. A sugestão é de que o personagem pode ser um boneco, uma coisa, um monstro, ele não está no plano da humanidade, mas da brincadeira, descrito no posfácio de Ninfa Parreiras.

Tais imagens que desvalorizam características fenotípicas, usadas em meados do século XVIII e XIX, deterministas e com o propósito de inferiorizar não-brancos, ressurgem agora na fusão entre corpo (lábios e nariz agigantados) na história e desumanizam a figura para o riso fácil. Em artigo especifico sobre a representação estereotipada de negros na sociedade por meio da mídia, Jonathas Vilas Boas de Sant'ana (2017) discute que, historicamente, negros foram representados com olhos grandes, boca grande, disformes e sem humanidade em diferentes representações, sem representação cultural e identidade, com corpos feitos para divertir e rir. Assim, associar a ilustração à estereotipia é uma função acadêmica e que os estudos revelam (LOPES, 2012; SILVA; ROSEMBERG, 2008). As imagens norte-americanas enfatizavam as tendências americanas das leis Jim Crow que, com base no cientificismo, afirmaram a segregação nos Estados Unidos na tentativa de inferiorizar os negros. 0 termo Crow, corvos, vem da referência aos escravizados. Um comediante de nome Thomas D. Rice explorou uma figura sem identidade como personagem, utilizando blackface, e utilizou como nome Jim Crow, o que motivou o nome da lei posteriormente. Ele insistia em atribuir atitudes ridículas e desumanas aos negros por meio da personagem, estratégia social de inferiorizar não-brancos e conter a voz de negros e negras na América que denunciavam e não aceitavam este tratamento. 0 termo Golliwog, nome dos 
bonequinhos de trapo, típicos das histórias infantis do século XIX, trazem a criança negra com traços exagerados que influenciaram tendências iconográficas nas ilustrações mundiais (LARRICK, 1965). As crianças negras eram então chamadas de pickaninny para lembrar a referência a golliwogs e golly dolls com a insistência em desumanizar as crianças, pois não precisavam de cuidados, eram malandras o suficiente e podiam se cuidar sozinhas (HARRIS, 1993). Ainda nesta linha, a figura da mammy, uma negra gorda, com seios cheios de leite para amamentar muitas crianças brancas, tinha como sina ser doméstica e influenciou as imagens em desenhos, mídia e ilustrações mundialmente. Portanto, diante dessas ações de segregação denunciadas, conclui-se que: "The selective tradition in children literature regarding African americans has been replete whith stereotypes" (HARRIS, 1993, p. 168). ${ }^{5}$ E, nesta mesma tradição de estereotipias, o livro Quando os tam-tans fazem tum-tum (ZIGG, 2013) circula desde os anos de 1990 e, mesmo após a implementação da Lei no 10.639 , de 2003 (BRASIL, 2003), mantém a mesma ilustração do personagem principal associado às imagens de estereotipias de afro-americanos, e concerne com os estudos anteriores que marcam o padrão de humanidade como branco (DADIE, 2013; FERNANDES; PAULA, 2015; FERREIRA, 2012, 2014b; KAERCHER, 2006; OLIVEIRA, 2010).

\section{Conclusões}

A análise das políticas de leitura para a educação infantil do município de Curitiba revelou um campo complexo e multifacetado. 0 conjunto de dados de que dispomos apresenta discursos em disputa, com múltiplas interferências nas políticas do livro.

No plano de gestão do sistema, encontramos uma organização da Secretaria Municipal de

5 "A tradição seletiva na literatura infantil sobre os afro-americanos foi repleta de estereótipos." (HARRIS, 1993, p. 168, tradução nossa).
Educação que apresenta política de letramento, em alguma medida influenciada pelas políticas federais de distribuição de livros, mas com autonomia desta tanto em algumas das definições locais quanto na composição dos acervos.

Tanto as gestoras do sistema quanto as representantes de equipes pedagógicas demonstraram informações e reconhecimento de obras de literatura de temática africana e afro-brasileira e do seu possível papel na educação das relações étnico-raciais. No entanto, em ambos os grupos, de forma um tanto inicial e tênue, com tendência a operar com generalismos. De forma similar às normativas municipais, que incorporaram de forma tênue as diretrizes da educação das relações étnico-raciais.

Do ponto de vista da gestão, observou-se um trabalho de orientação de políticas de leitura, de gestão e controle do sistema e dos acervos, de busca de indicadores de qualidade das obras e das práticas de letramentos. Entretanto, do ponto de vista de orientações e qualidade para a igualdade racial e para a diversidade com estratégias e discursos, bastante limitado.

A composição dos acervos também mostrou bastante heterogeneidade, assim como práticas de leitura relatadas e observadas. Uma diferença bastante significativa foi observada entre a unidade conveniada, a escola municipal com oferta de turma de Educação Infantil, e os Centros Municipais de Educação Infantil, resultado que é relevante no momento em que as políticas de financiamento e as orientações de sistema operam para retrocessos. A diferença qualitativa entre as instituições públicas e a conveniada é mais um resultado que se agrega à necessidade de outra via para que a educação infantil se dirija para a qualidade.

A unidade conveniada possuía, no momento da pesquisa, um acervo com mais de 600 livros para consulta, localizado distante da sala de aula, os livros todos muito antigos, utilizados conforme a solicitação das professoras. A sala de referência possuía em torno de 70 livros para as professoras selecionarem alguns e os incluírem no acervo e nas atividades de leitu- 
ras organizadas diariamente. Dentre a maioria dos livros dispostos nas prateleiras para as crianças, os contos de fada, os com ilustrações de animais e os com números muito coloridos eram os escolhidos, influência da disposição dos livros nas prateleiras.

Quando era para as crianças buscarem os livros que mais gostavam, as opções já estavam pré-definidas pelos livros dispostos nas prateleiras, com as capas visíveis e acessíveis às crianças. No referido acervo de cerca de 700 livros, não observamos livros dos programas de leitura do PNBE nem livros constantes na listagem de indicações dada pela Comissão da SME. A unidade conveniada recebe um valor específico, o qual pode ser utilizado para a aquisição de livros, contudo as demandas internas são variadas e o dinheiro serve ao propósito também de manutenção do local.

Os objetos livro encontrados neste acervo numericamente expressivo eram raras vezes de literatura e muito mais de personagens midiáticos com histórias colocadas em livros. A tendência geral era de livros de baixo custo e qualidade.

Na escola municipal que ofertava turmas de educação infantil também foi observado parte do acervo com essas características, livros sobre personagens midiáticos foram identificados, o que, segundo a análise de Steinberg (2001), sintetiza valores de consumismo e estrutura a normatividade branca.

Na mesma escola, por outro lado, na biblioteca o cuidado era outro, inclusive a mediadora de literatura organizou um tapete com várias imagens literárias, no qual ela sentava com as crianças para a mediação da leitura, onde fazia leituras dramatizadas e apresentava os livros para elas.

Com relação às práticas de leitura e aos acervos, observou-se também complexidade, com formas de valorização e afirmação de africanidades ao lado de formas de hierarquia e estereotipia. Como afirma Gomes (2002, p. 41), "Na instituição escolar, assim como na sociedade, nós comunicamos por meio do corpo.
Um corpo que é construído biologicamente e simbolicamente na cultura e na história." Essa trajetória individual é construída aos pares no ambiente escolar e no cotidiano social e nos revela a importância dos estudos das relações raciais em contextos de mediação de leitura. Os padrões estéticos podem rememorar aspectos culturais provenientes da hegemonia branca, como afirmação à naturalização da infância negra em representações e discursos literários importantes para influenciar os contextos de leitura e mediação com a literatura.

A análise do conjunto de dados da pesquisa nos permite a proposta de análise a partir dos conceitos discutidos por Aparecida Ferreira (2012, 2014a), de "letramento racial" e "letramento crítico racial" e sua integração com o campo de estudos sobre os "letramentos literários". Propormos para a análise do campo da educação das relações étnico-raciais o termo "letramentos literários raciais", já que as políticas de leitura e de educação infantil, os acervos e os livros de literatura infantil ainda estão proporcionalmente estruturados por uma branquidade normativa, silenciam outras identidades que não as brancas e, muitas vezes, com formas de estereotipia e discriminação.

Tais reflexões sustentam a proposta de uso do conceito de "letramentos literários crítico raciais" como proposta que tensiona o campo, e não como consolidada; como prática de políticas educacionais e de letramento que operem para o direito aos livros literários com qualidade. Tal qualidade se dirige ao exercício afirmativo do direito político em se efetivar na seleção, distribuição e leitura de livros com valorização de personagens negras e sem estereotipias, em um plano geral no combate antirracista.

Os discursos literários que operam em chave antirracista, que afirmam e difundem africanidades, que trazem em suas narrativas, ilustrações, personagens principais, narradoras(es), temas ou contextos, de forma conjugada ou não, mas que operam para a valorização da negritude e dialogam com práticas de letramento 
de educação das relações étnico-raciais, têm potencial de letramento literário crítico racial, de operar numa educação que promova em crianças negras e crianças brancas, assim como em crianças indígenas e crianças "amarelas", o respeito ao outro, a concepção de relações não hierarquizadas, a igualdade étnico-racial. Enfim, nossa proposta é de reservar o termo para obras, acervos e práticas pedagógicas de letramento que promovam a educação antirracista, que promovam a reciprocidade e a igualdade.

\section{REFERÊNCIAS}

ALCARAZ, Rita de Cássia Moser. Políticas de leitura para a infância no município de Curitiba: o livro como direito à promoção de igualdade racial. 2018. 243f. Tese (Doutorado em Educação) - Universidade Federal do Paraná (UFPR), Curitiba, 2018. Disponível em: https://acervodigital.ufpr. br/handle/1884/58584. Acesso em: 05 mar. 2021.

ALMEIDA, Gersilga. Bruna e a galinha D'Angola. Rio de Janeiro: Pallas, 2004.

ARAUJO, Débora Cristina. Literatura infantojuvenil e política educacional: estratégias de racialização no Programa Nacional de Biblioteca da Escola (PNBE). 2015. 335 f. Tese (Doutorado em Educação) - Faculdade de Educação, Universidade Federal do Paraná (UFPR), Curitiba, 2015. Disponível em: https://acervodigital.ufpr.br/ handle/1884/38010. Acesso em: 05 mar. 2021.

ARAÚJO, Debora Cristina; SILVA, Paulo Vinicius Baptista. Contribuições dos estudos críticos sobre relações étnico-raciais ao campo da Educação. Revista Teias, v. 21, n. 62, jul./set. 2020. Disponível em: https://www.e-publicacoes.uerj.br/index. $\mathrm{php/revistateias/article/view/49670/35070.}$ Acesso em: 05 mar. 2021.

BARBOSA, Rogério de Andrade. Karingana wa Karingana: histórias que me contaram em Moçambique. São Paulo: Paulinas, 2012.

BARTON, David. Literacy: an introduction to the ecology of written language. Oxford: Blackwell, 1994.

BENJAMIN, Walter. Reflexões: a criança, o brinquedo, a educação. São Paulo: Summus, 1984.

BELÉM, Valéria. 0 cabelo de Lelê. Ilustrações de Adriana Mendonça. São Paulo: IBEP/Nacional, 2012.
BRASIL. Presidência da República. Casa Civil. Lei no 10.639, de 09 de janeiro de 2003. Altera a Lei ${ }^{\circ}$ 9.394, de 20 de dezembro de 1996, que estabelece as diretrizes e bases da educação nacional, para incluir no currículo oficial da Rede de Ensino a obrigatoriedade da temática "História e Cultura Afro-Brasileira", e dá outras providências. Brasília, DF, 2003. Disponível em: http://www. planalto.gov.br/ccivil_03/leis/2003/110.639.htm. Acesso em: 30 maio 2021.

BRASIL. Presidência da República. Casa Civil. Lei no 11.645, de 10 de março de 2008. Altera a Lei $\mathrm{n}^{\circ}$ 9.394, de 20 de dezembro de 1996, modificada pela Lei $\mathrm{n}^{0} 10.639$, de 9 de janeiro de 2003, que estabelece as diretrizes e bases da educação nacional, para incluir no currículo oficial da rede de ensino a obrigatoriedade da temática "História e Cultura Afro-Brasileira e Indígena". Brasília, DF, 2008. Disponível em: http://www.planalto.gov.br/ ccivil_03/_ato2007-2010/2008/lei/l11645.htm. Acesso em: 30 maio 2021.

CIRANDA CULTURAL. Diversidade - somos diferentes, únicos e especiais. São Paulo: Ciranda Cultural, 2010.

COOKE, Trish. Tanto, tanto! São Paulo: Ática, 1997. (Coleção Giramundo).

COSSON, Rildo. Letramento literário: teoria e prática. São Paulo: Contexto, 2006.

CORRÊA, Mariza. Sobre a invenção da mulata. Cadernos Pagu, n. 6-7, p. 35-50, 1996:

Disponível em: https://periodicos.sbu.unicamp.br/ ojs/index.php/cadpagu/article/view/1860. Acesso em: 05 mar. 2021.

CURITIBA. Prefeitura Municipal de Curitiba (PMC). Secretaria Municipal de Educação (SME). Rede Municipal de Bibliotecas de Curitiba. Caderno Pedagógico. Curitiba: PMC/SME, 2014.

CURITIBA. Prefeitura Municipal de Curitiba (PMC). Secretaria Municipal de Educação (SME). Parâmetros e indicadores de qualidade para os centros municipais de Educação Infantil. Curitiba: PMC/SME, 2009. Disponível em: http:// multimidia.educacao.curitiba.pr.gov.br/2015/10/ pdf/00087009.pdf. Acesso em: 05 jun. 2019.

DADIE, Gilmara Aparecida Guedes dos Santos. Personagens negros, protagonistas nos livros da educação infantil: estudo do acervo de uma escola de educação infantil do município de São Paulo. 2013. 171 f. Dissertação (Mestrado em Educação) - Programa de Pós-Graduação em 
Educação, Faculdade de Educação, Universidade de São Paulo (USP), São Paulo, 2013.

DEBUS, Eliane Santana Dias. A palavra poética na infância: a que $(m)$ será que se des(a)tina. In: PEIXE, Débora Cristina de Sampaio; BRAGAGNOLO, Regina Ingrid; CONDE, Soraya Franzoni (org.). Desafios e perspectivas da formação continuada de professores de educação infantil em Santa Catarina. v. 1.1. ed. Florianópolis: NUP/UFSC, 2016. p. 151-168.

DEBUS, Eliane Santana Dias. A temática da cultura africana e afro-brasileira na literatura para crianças e jovens. Florianópolis: NUP, 2017.

DIOUF, Sylviane Anna. As tranças de Bintou. 2. ed. Tradução Charles Cosac. São Paulo: Cosac Naify, 2004.

DON, Wood. 0 rei Bigodeira e a sua banheira. 2. ed. São Paulo: Ática, 2010.

ESPINHEIRA Filho, Ivan de Pinho. As poéticas negras brasileiras nos livros didáticos de Língua Portuguesa do Ensino Médio: ausências, presenças e possibilidades de uma educação antirracista. 2020. 309f. Tese (Doutorado em Educação) - Programa de Pós-graduação em Educação, Universidade Federal de Minas Gerais (UFMG), Belo Horizonte, 2020. Disponível em: https://repositorio.ufmg.br/handle/1843/35528. Acesso em: 07 jun. 2021.

FANON, Frantz. Pele negra, máscaras brancas. Tradução de Renato da Silveira. Salvador: EDUFBA, 2008.

FERNANDES, Célia Regina Delácio; PAULA, Flávia Ferreira de. Literatura, infância e o projeto literatura em minha casa. Revista Teias, v. 16, n. 41, p. 72-88, 2015. Disponível em: https://www.epublicacoes.uerj.br/index.php/revistateias / article/view/24514. Acesso em: 05 mar. 2021.

FERREIRA, Aparecida de Jesus. Identidades sociais, letramento visual e letramento crítico: imagens na mídia acerca de raça/etnia. Trabalhos em Linguística Aplicada, Campinas, SP, v. 1, n. 51, p. 193-215, jan./jun. 2012. Disponível em: http:// www.scieorienta lo.br/pdf/tla/v51n1/v51n1a10. pdf. Acesso em: 12 fev. 2015.

FERREIRA, Aparecida de Jesus. Teoria racial crítica e letramento racial crítico: narrativas e contranarrativas de identidade racial de professores de línguas. Revista da ABPN, v. 6, n. 14, p. 236-263, jul./out. 2014a. Disponível em: https: / / d 1wqtxts1xzle7.cloudfront. net/35618883/2014_ABPN_letramento_racial_
critico_e_teoria_racial_critica_Aparecida_Ferreira_. pdf?1416287330=\&response-content-dispos ition=inline \%3B+filename\%3DTeoria_Racial_ Critica_e_Letramento_Racia.pdf\&Expires $=16149$ 88157\&Signature $=$ PvdeFmq920k0jI8I54YhQVR uWQ2dAFNFazLkCHPjrALoQ16KApPw3jnbxZV2 V22cxPeS9Eq2ff1x6lscImMZksFfbDd3oboaCX1C mZMgNigHfsCrt-5KXGolm1ROnhNqOF3A5Nix2ed -EzCNrVZEB4X $\sim$ FdkxPgSI-SuezIwssMAE pHD9Y9SXgfdApuffp9ZbPwlPrDMGKhITKJZj 6cPXNOFKrggupUqdz7Ke9EiVFK5Xoz4RYiG TaLV1-d118cm2vvGaLFNhCIRILOZIN8LOTXf TYNX47nJT3tETycORV7rjDWdRtNoABtANVi Yq-BDWdJlLMn 47C9vc $\sim$ w0Wk $\sim$ bA_\&Key-PairId=APKAJLOHF5GGSLRBV4ZA. Acesso em: 05 mar. 2021.

FERREIRA, Aparecida de Jesus. Identidades Sociais de Raça, Gênero, Sexualidade e Classe nos Livros Didáticos de Língua Estrangeira na Perspectiva da Linguística Aplicada. In: FERREIRA, Aparecida de Jesus (org.). As políticas do livro didático e identidades sociais de raça, gênero, sexualidade e classe em livros didáticos. Campinas, SP: Pontes, 2014b. p. 91-120.

GODOY, Célia. Ana e Ana. Ilustrações de Fê. São Paulo: DCL, 2004.

GOMES, Nilma Lino. Trajetórias escolares, corpo negro e cabelo crespo: reprodução de estereótipos ou ressignificação cultural? Revista Brasileira de Educação, Rio de Janeiro, n. 21, p. 40-51, set./dez. 2002. Disponível em: http://www. scielo.br/scielo.php?script=sci_arttext\&pid $=$ S1413-24782002000300004. Acesso em: 11 jul. 2015.

HARRIS, Violet J. African American Children's Literature. In: PERRY, Theresa; FRASER, James W. (ed.).Freedom's Plow: teaching in the multicultural classroom, 1993. p. 167.

HUNT, Peter. Crítica, teoria e literatura infantil. Tradução de Cid Knipel. São Paulo: Cosacnaify, 2010.

KAERCHER, Gládis Elise Pereira da Silva. 0 mundo na caixa: gênero e raça no Programa Nacional de Biblioteca da Escola. 2006. 225 f. Tese (Doutorado em Educação) - Programa de Pós-Graduação em Educação, Universidade Federal do Rio Grande do Sul (UFRGS), Porto Alegre, 2006.

KINNEY, Jeff. Diário de um banana. Trad. Antonio Soares de Macedo. São Paulo: V\&R, 2008.

KLEIMAN, Angela B. (org.). Os significados do letramento: uma nova perspectiva sobre a prática 
social da escrita. Campinas, SP: Mercado das Letras, 1995.

LARRICK, Nancy. The all white world of children's books. Chap. In: OSA, Osayimwense (ed.). The all white world of children's books and african american children's literature. Atlanta: Africa World, 1965. p. 1-12.

LIMA, Graça. Cadê? São Paulo: Nova Fronteira, 2009.

LIMA, Heloisa Pires. Histórias da Preta. Ilustrações de Laura Beatriz. São Paulo: Cia das Letrinhas, 1998.

LOPES, Naiane Rufino. Programa Nacional Biblioteca da Escola (PNBE) 2010: personagens negros como protagonistas e a construção da identidade étnico-racial. 2012. 156 f. Dissertação (Mestrado em Educação) - Programa de Pós-Graduação em Educação, Universidade Estadual Paulista "Júlio de Mesquita Filho" (UNESP), Marília, SP, 2012.

MACHADO, Ana Maria. Menina bonita do laço de fita. São Paulo: Ática, 2011.

MARCUSCHI, Luiz Antônio. Letramento e oralidade no contexto das práticas sociais e eventos comunicativos. In: SIGNORINI, Inês (org.). Investigando a relação oral/escrito e as teorias do letramento. Campinas, SP: Mercado de Letras, 2001. p. 23-50.

NEVES, André. Obax. São Paulo: Brinque-Book, 2010.

OLIVEIRA, Verediane Cintia de Souza Oliveira. Educação das relações étnico-raciais e estratégias ideológicas no acervo do PNBE 2008 para educação infantil. 2010.190 f. Dissertação (Mestrado em Educação) - Programa de Pós-Graduação em Educação, Universidade Federal do Paraná (UFPR), Curitiba, 2010.

OTERO, Regina. Ninguém é igual a ninguém. São Paulo: Editora do Brasil, 2008.

PAULINO, Graça; COSSON, Rildo. Letramento literário: para viver a literatura dentro e fora da escola. In: ZILBERMAN, Regina; RÖSING, Tania (org.). Escola e leitura: velha crise; novas alternativas. São Paulo: Global, 2009. p. 61-80.

ROJO, Roxane. Letramento escolar, oralidade e escrita em sala de aula: diferentes modalidades ou gêneros do discurso? In: SIGNORINI, Inês (org.). Investigando a relação oral/escrito e as teorias do letramento. Campinas, SP: Mercado de Letras, 2001. p. 51-74.
RUMFORD, James. Chuva de manga. Ilustrações de James Rumford. São Paulo: Brinque-Book, 2005.

SAGEZZA. Direitos e deveres das crianças. São Paulo: Sagezza, 2008.

SANT'ANA, Jonathas Vilas Boas. Colonialidade na mídia: imagens estereotipadas de negros. Revista Fórum Identidades, v. 24, p. 141-155, 2017.

SANTOS, Joel R. Gosto de África: histórias daqui e de lá. São Paulo: Martins Fontes, 2000.

SILVA, Paulo Vinicius Baptista; ROSEMBERG, Fúlvia. Brasil: lugares de negros e brancos na mídia. In: VAN DIJK, Teun (org.). Racismo e discurso na América Latina. São Paulo: Contexto, 2008. p. 73-119.

SILVA, Paulo Vinicius Baptista; SOUZA, Gizele de. Relações étnico-raciais e práticas pedagógicas em Educação Infantil. Educar em Revista, Curitiba, n. 47, p. 35-50, jan./mar. 2013. Disponível em: https://www.scielo.br/pdf/er/n47/04.pdf. Acesso em: 05 mar. 2021.

SOUZA, Sidnei Marinho de. Novas iconografias no livro didático de História: análise e recepção do racismo e antirracismo imagético por jovens do ensino médio. 2021. Tese (Doutorado em Educação) - Universidade Federal de Minas Gerais (UFMG), Belo Horizonte, 2021.

STEINBERG, Shirley. A mimada que tem tudo. In: STEINBERG, Shirley; KINCHELOE, Joe (org.). Cultura infantil: a construção corporativa da infância. Rio de Janeiro: Civilização Brasileira, 2001. p. 321338.

STEPHENS, Jonh; McCALLUM, Robyn. Ideology and children's book's. In: WOLF, Shelby et al. Handbook of research on children's and young adult literature. New York: Routledge, 2011. p. 359-371.

STREET, Brian V. Letramentos sociais: abordagens críticas do letramento no desenvolvimento, na etnografia e na educação. Tradução Marcos Bagno. 1. ed. São Paulo: Parábola, 2014.

STREET, Brian V. (ed.). Literacy and development: ethnographic perspectives. London: Routledge, 2001.

STREET, Brian V.Políticas e práticas de letramento na Inglaterra: uma perspectiva de letramentos sociais como base para uma comparação como Brasil. Cadernos CEDES, Campinas, SP, v. 33, n. 89, jan./abr. 2013. Disponível em: https://www.scielo.br/scielo. php?pid=S0101-32622013000100004\&script=sci_ abstract\&tlng=pt. Acesso em: 05 mar. 2021. 
VAN DIJK, Teun A. Discurso e poder. São Paulo: Contexto, 2015.

WOOD, Audrey. 0 rei bigodeira e sua banheira. ZIRALDO. 0 menino marrom. São Paulo: Trad. Gisela Maria Padovan. São Paulo: Ática, 2010. Melhoramentos, 1986.

Recebido em: 05/05/2021 Aprovado em: 16/05/2021 